\title{
Efficacy of tadalafil treatment on erectile dysfunction in patients under dutasteride treatment: A prospective non-randomized comparative study
}

\author{
Mete Özkıdık (D), Mehmet İlker Gökce (DD, Önder Yaman (D)
}

Cite this article as: Özkıdık M, Gökce Mİ, Yaman Ö. Efficacy of tadalafil treatment on erectile dysfunction in patients under dutasteride treatment: A prospective non-randomized comparative study. Turk J Urol 2018; 44: 294-7.

ORCID IDs of the authors: M.Ö. 0000-0002-7304-9396; M.I.G. $0000-0002-2370-548 X$; Ö.Y. 0000-0001-6202-4663.

Department of Urology, Ankara University School of Medicine, Ankara, Turkey

Submitted:

16.09.2017

Accepted:

29.12.2017

Available Online Date: 09.03.2018

Correspondence: Mehmet Illker Gökce E-mail:migokce@yahoo.com (C) Copyright 2018 by Turkish Association of Urology

Available online at www.turkishjournalofurology.com

\begin{abstract}
Objective: In this study, we aimed to evaluate the efficacy of tadalafil in the management of erectile dysfunction in patients under dutasteride medication for bladder outlet obstruction.

Material and methods: In this study the data of consecutive patients that admitted to our outpatient clinics treated with dutasteride for bladder outlet obstruction and tadalafil (10 or $20 \mathrm{mg}$ on demand) for concomitant complaint of erectile dysfunction (ED) between October 2013 and March 2016 were evaluated. An agematched control group of patients treated with tadalafil for ED but did not receive any other medication for either lower urinary tract symptoms (LUTS) or ED was also included. Groups were compared for tadalafil efficacy with International Index of Erectile Function (IIEF) scores.
\end{abstract}

Results: Each one of the dutasteride and control groups included 104 patients. The groups were similar for pretreatment IIEF score, serum cholesterol, low-density lipoprotein (LDL), triglyceride and testosterone measurements. The number of hypertensive patients was comparable between two groups but the number of diabetic patients were significantly higher in the control group. IIEF score improved significantly in both groups following tadalafil treatment but the difference between the two groups was not statistically significant.

Conclusion: Tadalafil treatment provides significant improvement in erectile functions of patients under dutasteride treatment for bladder outlet obstruction. However, the current study does not focus on a population of dutasteride induced ED and therefore a further prospective study on this issue would be helpful.

Keywords: Dutasteride; erectile dysfunction; IIEF; tadalafil.

\section{Introduction}

Dutasteride is a 5-alpha reductase inhibitor (5ARI) and blocks the enzyme that is responsible for the conversion of testosterone to its bioactive form dihydrotestosterone. ${ }^{[1]}$ Dutasteride is mainly used in the management of benign prostatic hyperplasia $(\mathrm{BPH})$ and currently recommended for this indication by the EAU and AUA guidelines. ${ }^{[2,3]}$ There is controversy on the effect of 5ARIs on sexual functions. A recent meta-analysis of randomized controlled trials reported 5ARIs to be associated with adverse effects on sexual function in men with $\mathrm{BPH}$ compared with placebo. ${ }^{[4]}$ However, in a population-based study including 71,849 men 5ARIs were not found to significantly increase the risk of incident erectile dysfunction. ${ }^{[5]}$
Tadalafil is a phosphodiesterase type 5 inhibitor (PDE5i) and has been shown to be effective in the treatment of erectile dysfunction (ED) compared to placebo. ${ }^{[6,7]}$ Tadalafil is also an alternative in the management of bladder outlet obstruction. ${ }^{[2]}$ In a recent prospective randomized study, co-administration of tadalafil and finasteride has been shown to be more effective when compared with finasteride alone for the management of BPH-related symptoms and also provided better erectile functions. ${ }^{[8]}$

Although clinical efficacy of dutasteride and tadalafil is proved for the indications of $\mathrm{BPH}$ and ED respectively, the efficacy of tadalafil for treatment of erectile dysfunction in patients under dutasteride treatment for the symptoms of $\mathrm{BPH}$ has not been studied previously and the objective of the current study was to evaluate the efficacy 
of tadalafil in the management of erectile dysfunction in patients under dutasteride medication for bladder outlet obstruction.

\section{Material and methods}

In this study the data of consecutive patients who were admitted to our outpatient clinics with the complaints of lower urinary tract symptoms (LUTS) and treated with dutasteride between October 2013 and March 2016 were evaluated. Among these patients, the patients who were prescribed tadalafil (10 or $20 \mathrm{mg}$ on demand) for concomitant complaint of ED were selected for analysis and an age-matched control group of patients treated with tadalafil for ED but did not receive any other medication for either LUTS or ED was also included.

The inclusion criteria were as follows: presence of normal libido, International Index of Erectile Function (IIEF) $<17$, non-usage of PDE5i, and normal serum testosterone levels (>300 ng/mL). Patients who had previous prostatic or penile reconstruction surgery and received intracavernosal injection therapies were excluded from the analysis. Data on age, presence of diabetes mellitus (DM), serum cholesterol, low-density lipoprotein (LDL), and triglyceride levels and presence of hypertension were collected. Patients were evaluated with IIEF for ED prior to inclusion and at third and sixth months of the treatment. Serum free testosterone levels were also measured.

\section{Statistical analysis}

The primary endpoint of the study was to compare the erectile functions of the patients as a response to tadalafil therapy in the

\begin{tabular}{|c|c|c|c|}
\hline Parameters & $\begin{array}{c}\text { Dutasteride } \\
\text { group } \\
(n=104)\end{array}$ & $\begin{array}{l}\text { Control } \\
\text { group } \\
(n=104)\end{array}$ & $\mathbf{p}$ \\
\hline $\mathrm{IIEF}$, mean $\pm \mathrm{SD}$ & $12.2 \pm 3.3$ & $11.9 \pm 3.1$ & 0.53 \\
\hline Diabetes mellitus, n (\%) & $12(11.5)$ & $23(22.1)$ & 0.04 \\
\hline Hypertension, n (\%) & $17(16.3)$ & $18(17.3)$ & 0.85 \\
\hline $\begin{array}{l}\text { Serum testosterone } \\
(\mathrm{ng} / \mathrm{mL}), \text { mean } \pm \mathrm{SD}\end{array}$ & $321.1 \pm 58.6$ & $339.6 \pm 61.2$ & 0.27 \\
\hline $\begin{array}{l}\text { Serum cholesterol } \\
(\mathrm{mg} / \mathrm{dL}), \text { mean } \pm \mathrm{SD}\end{array}$ & $198.2 \pm 30.6$ & $189.3 \pm 28.1$ & 0.31 \\
\hline $\begin{array}{l}\text { Serum LDL }(\mathrm{mg} / \mathrm{dL}), \\
\text { mean } \pm \mathrm{SD}\end{array}$ & $125.3 \pm 11.2$ & $121.6 \pm 9.8$ & 0.52 \\
\hline $\begin{array}{l}\text { Serum triglyceride } \\
(\mathrm{mg} / \mathrm{dL}), \text { mean } \pm \mathrm{SD}\end{array}$ & $155.8 \pm 20.6$ & $149.9 \pm 19.9$ & 0.55 \\
\hline \multicolumn{4}{|c|}{ IIEF: International Index of Erectile Function } \\
\hline
\end{tabular}

dutasteride and control groups. Statistical analysis was performed with IBM Statistical Package for the Social Sciences Statistics for Windows, Version 20.0. (IBM SPSS Statistics; Armonk, NY, USA). The descriptive statistics for the parameters were provided. The dutasteride and control groups were compared with unpaired t-test or Mann-Whitney U test for the continuous variables and chi-Square test or Fisher's exact test for the categorical variables. Logistic regression analysis was performed to define effect of dutasteride use on response rates to tadalafil. For statistical significance $\mathrm{p}$ value of 0.05 was accepted.

\section{Results}

A total of 104 patients were included in the dutasteride group and the age-matched control group also consisted of 104 patients. The mean age of the population was 61.2 \pm 8.9 years. The groups were similar for mean IIEF scores, serum cholesterol, LDL and triglyceride measurements, presence of hypertension, and serum testosterone levels. However, patients in the control group were found to have higher rate of DM. The results are summarized in Table 1.

The groups are compared for the degree of improvement in the IIEF scores following tadalafil treatment $(\mathrm{p}<0.001$ for both groups). Significant improvement in IIEF scores was observed in both groups. The mean IIEF scores of dutasteride and control groups were $21.1 \pm 5.5$ and $21.9 \pm 5.8(\mathrm{p}=0.59)$, respectively. The mean IIEF scores before and after tadalafil treatment are summarized in Figure 1.

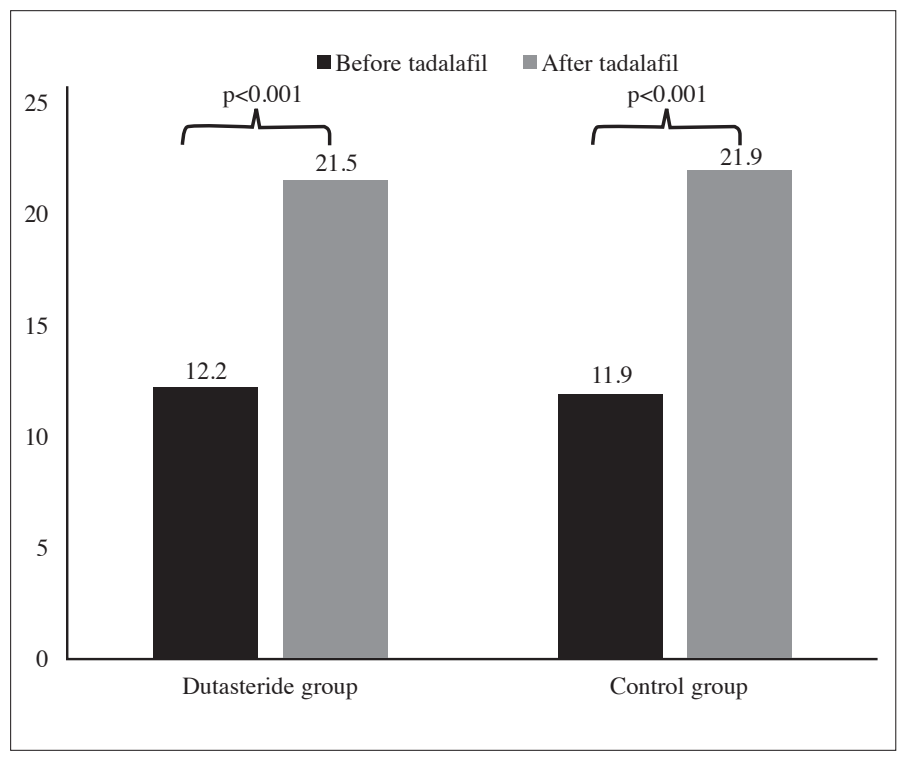

Figure 1. Mean IIEF scores of the dutasteride and control groups before and after tadalafil treatment

IIEF: International Index of Erectile Function 


\section{Discussion}

PDE5i's are the first line medical treatment for ED and tadalafil has been reported to be an effective and unique agent with its longer plasma half-life. ${ }^{[6,7]}$ In the current study tadalafil is shown to be effective for the treatment of ED in patients receiving dutasteride for the management of bladder outlet obstruction.

Tadalafil is one of PDE5i's and one of the primary options in the medical management of ED. Tadalafil is recommended either as 10 or $20 \mathrm{mg}$ doses for on-demand use or daily of $5 \mathrm{mg}$. Clinical efficacy has been shown in up to $81 \%$ of the ED patients. ${ }^{[6]}$ However, efficacy of tadalafil depends on other medical conditions as well and the aim of the current study was to compare the efficacy of tadalafil treatment for ED in two populations receiving of not receiving dutasteride treatment.

Dutasteride together with the other 5 alpha reductase inhibitor, finasteride, reduces the prostate volume and therefore alleviates the risk of acute urinary retention and surgery. Its mechanism of action involves blockage of the conversion of testosterone to its bioavailable form dihydrotestosterone. ${ }^{[1]}$ Due to its effect on testosterone metabolism, dutasteride is blamed for adverse effects on sexual functions. Persistent ED, decreased libido and ejaculatory dysfunction have been reported in a number of studies..$^{[4,9]}$ In a recent meta-analysis, the risk of ED was higher in 5ARItreated patients than in placebo treated patients ${ }^{[4]}$ However, In a recent population-based study Hagberg et al. ${ }^{[5]}$ reported no adverse relation between 5-alpha reductase inhibitor use and erectile functions in patients. Although the results of the studies show controversies about the effect of dutasteride on erectile functions, elderly population is the target for the prescription of both dutasteride and tadalafil and therefore, we believe that the evaluation of the response of tadalafil in dutasteride users is important.

In our study significant improvement in the IIEF score was observed in both dutasteride and the control groups following tadalafil treatment. Although we did not zdetermine whether ED developed due to dutasteride treatment or not in the study group, patients responded well to tadalafil treatment. Increase in IIEF scores following tadalafil treatment was seen regardless of the use of dutasteride as also reported in a previously published study by Janini et al. ${ }^{[10]}$

The most important drawback of our study is the lack of randomization with placebo in both groups. Additionally, in our study group we did not determine whether the development of ED was related or unrelated to dutasteride use. Therefore, the favorable response to tadalafil treatment in the dutasteride group cannot be generalized, and associated with 5 alpha- reductase inhibitor related ED. On the other hand, to the best of our knowledge, this is the first study that evaluates the tadalafil response in patients under dutasteride treatment.

In conclusion, tadalafil treatment provides significant improvement in erectile function of the patients under dutasteride treatment for bladder outlet obstruction. Also the results of the current study proves that dutasteride treatment does not have a negative impact on response to tadalafil among ED patients. However, the current study does not focus on a population of dutasteride-induced ED and therefore conduction of a further prospective study on this issue would be helpful.

Ethics Committee Approval: Authors did not get review board approval as the data was analyzed in a retrospective study.

Informed Consent: Written informed consent was obtained from all patients who participated in this study.

Peer-review: Externally peer-reviewed.

Author Contributions: Concept-Ö.Y., M.Ö.; Design-Ö.Y., M.Ö.; Supervision-M.İ.G., Ö.Y.; Data Collection and/or Processing-M.Ö., M.İ.G.; Analysis and/or Interpretation-Ö.Y., M.Ö., M.İ.G.; Literature Search-M.Ö., M.İ.G.; Writing Manuscript-M.Ö., Ö.Y., M.İ.G.; Critical Review-Ö.Y.

Conflict of Interest: Authors have no conflicts of interest to declare.

Financial Disclosure: The authors declared that this study has received no financial support.

\section{References}

1. Clark RV, Hermann DJ, Cunningham GR, Wilson TH, Morrill BB, Hobbs S. Marked suppression of dihydrotestosterone in men with benign prostatic hyperplasia by dutasteride, a dual 5alpha-reductase inhibitor. J Clin Endocrinol Metab 2004;89:2179-84. [Crossref]

2. Gratzke C, Bachmann A, Descazeaud A, Drake MJ, Madersbacher $\mathrm{S}$, Mamoulakis C, et al. EAU Guidelines on the Assessment of Nonneurogenic Male Lower Urinary Tract Symptoms including Benign Prostatic Obstruction. Eur Urol 2015;67:1099-109. [Crossref]

3. McVary KT, Roehrborn CG, Avins AL, Barry MJ, Bruskewitz $\mathrm{RC}$, Donnell RF, et al. Update on AUA guideline on the management of benign prostatic hyperplasia. J Urol 2011;185:1793-803. [Crossref]

4. Liu L, Zhao S, Li F, Li E, Kang R, Luo L, et al. Effect of 5alphaReductase Inhibitors on Sexual Function: A Meta-Analysis and Systematic Review of Randomized Controlled Trials. J Sex Med 2016;13:1297-310. [Crossref]

5. Hagberg KW, Divan HA, Persson R, Nickel JC, Jick SS. Risk of erectile dysfunction associated with use of 5-alpha reductase inhibitors for benign prostatic hyperplasia or alopecia: population based studies using the Clinical Practice Research Datalink. BMJ 2016;354:i4823. [Crossref] 
6. Curran M, Keating G. Tadalafil. Drugs 2003;63:2203-14. [Crossref]

7. Hakky TS, Jain L. Current use of phosphodiesterase inhibitors in urology. Turk J Urol 2015;41:88-92. [Crossref]

8. Glina S, Roehrborn CG, Esen A, Plekhanov A, Sorsaburu S, Henneges C, et al. Sexual function in men with lower urinary tract symptoms and prostatic enlargement secondary to benign prostatic hyperplasia: results of a 6-month, randomized, doubleblind, placebo-controlled study of tadalafil coadministered with finasteride. J Sex Med 2015;12:129-38. [Crossref]
9. Roehrborn CG, Boyle P, Nickel JC, Hoefner K, Andriole G, Aria A, et al. Efficacy and safety of a dual inhibitor of 5-alphareductase types 1 and 2 (dutasteride) in men with benign prostatic hyperplasia. Urology 2002;60:434-41. [Crossref]

10. Jannini EA, Isidori AM, Gravina GL, Aversa A, Balercia G, Bocchio M, et al. The ENDOTRIAL study: a spontaneous, openlabel, randomized, multicenter, crossover study on the efficacy of sildenafil, tadalafil, and vardenafil in the treatment of erectile dysfunction. J Sex Med 2009;6:2547-60. [Crossref] 